\title{
Improvement of physical stability properties of kenaf (Hibiscus cannabinus L.) seed oil- in-water nanoemulsions
}

\begin{abstract}
Kenaf seed oil-in-water nanoemulsions were optimised using simplex centroid mixture design with three components (sodium caseinate, gum Arabic and Tween 20). In addition, the main, binary and ternary interaction effects among these three selected emulsifiers on physical stability were also studied. The mixture design showed a good fit to the predicted model with R2 > 0.89, 0.82, and 0.73 for mean particle size, polydispersity index (PDI) and zeta-potential, respectively. The optimum proportion of emulsifier mixtures was $64.9 \%(\mathrm{w} / \mathrm{w})$ $\mathrm{SC}, 6.4 \%(\mathrm{w} / \mathrm{w}) \mathrm{GA}$, and $28.7 \%(\mathrm{w} / \mathrm{w}) \mathrm{T} 20$ that predicted to produce mean particle size of $126.82 \mathrm{~nm}$, PDI of 0.16 and zeta-potential of $\bar{\imath} 43.47 \mathrm{mV}$. The experimental value obtained was $121.22 \mathrm{~nm}, 0.16$ and $\bar{i} 39.63 \mathrm{mV}$ for mean particle size, PDI, and zeta-potential, respectively. No significant difference $(\mathrm{p}>0.05)$ between the experimental and predicted values, indicating the suitability of the mixture design for optimising and developing stable kenaf seed oil-in-water nanoemulsions. The optimised formulation was stable at both chill $\left(4^{\circ} \mathrm{C}\right)$ and room temperature $\left(25^{\circ} \mathrm{C}\right)$ over 1 month of evaluation. The results have important implications for the development of stable kenaf seed oil-based nutraceutical products. It can be added into beverages such as dairy products to improve the nutrition value of the beverage.
\end{abstract}

Keyword: Kenaf (Hibiscus cannabinus L.) seed oil; Nanoemulsions; High pressure homogenization; Emulsion stability 